\title{
Validation of the STOP-Bang questionnaire for screening of obstructive sleep apnea in the general population and commercial drivers: a systematic review and meta-analysis
}

\author{
Lina Chen ${ }^{1} \cdot$ Bianca Pivetta $^{1} \cdot$ Mahesh Nagappa $^{2} \cdot$ Aparna Saripella $^{1} \cdot$ Sazzadul Islam $^{1} \cdot$ Marina Englesakis $^{3} \cdot$ \\ Frances Chung ${ }^{1}$ iD
}

Received: 3 December 2020 / Revised: 5 January 2021 / Accepted: 15 January 2021 / Published online: 28 January 2021

(C) The Author(s) 2021

\begin{abstract}
Purpose Obstructive sleep apnea (OSA) is a critical occupational health concern, but is often undiagnosed in the general population and commercial drivers. The STOP-Bang questionnaire is a simple, reliable tool to screen for OSA, which could improve public health in a cost-effective manner. The objective of this systematic review and meta-analysis is to assess the validity of the STOP-Bang questionnaire to detect OSA in these key populations.

Methods We searched MEDLINE, Embase, Cochrane Central Register of Controlled Trials, Cochrane Database of Systematic Reviews, PsycINFO, Journals @ Ovid, Web of Science, Scopus, and CINAHL for relevant articles from 2008 to March 2020. The quality of studies was appraised using Cochrane Methods criteria. To calculate pooled predictive parameters, we created $2 \times$ 2 contingency tables and performed random-effects meta-analyses.

Results Of 3871 citations, five studies that evaluated STOP-Bang in the general population $(\mathrm{n}=8585)$ and two in commercial drivers $(n=185)$ were included. In the general population, prevalence of all OSA (AHI $\geq 5)$, moderate-to-severe OSA (AHI $\geq$ $15)$, and severe OSA ( $\mathrm{AHI} \geq 30)$ was $57.6 \%, 21.3 \%$, and $7.8 \%$ respectively. In commercial drivers, the prevalence of moderateto-severe OSA was $37.3 \%$. The trends of high sensitivity and negative predictive value of a STOP-Bang score $\geq 3$ illustrates that the questionnaire helps detect and rule out clinically significant OSA in the general population and commercial drivers.

Conclusion This meta-analysis demonstrates that the STOP-Bang questionnaire is a valid and effective screening tool for OSA in the general population and commercial drivers.
\end{abstract}

Trial registration PROSPERO No. CRD42020200379; 08/22/2020

Keywords Obstructive sleep apnea $\cdot$ Screening questionnaire $\cdot$ STOP-Bang questionnaire $\cdot$ General population $\cdot$ Commercial drivers

Lina Chen and Bianca Pivetta authors shared first authorship.

Frances Chung

frances.chung@uhn.ca

1 Department of Anesthesia and Pain Management, Toronto Western Hospital, University Health Network, University of Toronto, Toronto, Ontario, Canada

2 Department of Anesthesia and Perioperative Medicine, London Health Sciences Centre and St. Joseph Health Care, Western University, London, Ontario, Canada

3 Library \& Information Services, University Health Network, Toronto, Ontario, Canada

\section{Introduction}

Obstructive sleep apnea (OSA) is characterized by cessation of breathing during sleep, which leads to poor sleep patterns and daytime somnolence. OSA is an increasingly common sleep-breathing disorder and a substantial public health concern $[1,2]$. The reported prevalence of overall OSA in the general adult population ranges from 9 to $38 \%$ [3-5] with an estimated $80-90 \%$ of those individuals with OSA remaining undiagnosed [6, 7]. Among commercial drivers, who are a safety-sensitive occupational group, OSA is present in 24 $28 \%$ of the workforce $[8,9]$. If left undiagnosed and untreated, OSA can lead to serious health consequences including hypertension [10], cardiovascular diseases [11, 12], cognitive 
decline [13], depression [14], and all-cause mortality [15-17]. Furthermore, untreated OSA in non-commercial and commercial drivers has been strongly associated with an increased risk of motor vehicle accidents $[18,19]$. Considering the significant public health and safety burden of unrecognized sleep apnea, early identification of OSA to initiate treatment is crucial. Although overnight laboratory polysomnography (lab PSG) is the gold standard for diagnosing OSA, it is timeconsuming and costly. Portable or home sleep apnea testing (HSAT) may be more convenient but still requires the expertise of sleep medicine specialists for interpretation. Thus, a reliable screening tool that could facilitate early identification of at-risk individuals would be of tremendous help to healthcare professionals.

The STOP-Bang questionnaire screening tool is straightforward and self-reportable, and can be completed within 1 to 2 minutes [20,21]. It is comprised of four self-reportable criteria (STOP: Snoring, Tiredness, Observed apnea, and high blood Pressure) and four demographic items (Bang: BMI, age, neck circumference, gender). If individuals score 3 affirmative answers or more, they are classified as being at risk of OSA [22]. If individuals score 5 affirmative answers or more, they are considered to be at high risk of OSA [22]. In the surgical setting, the sensitivity of a STOP-Bang score $\geq 3$ is $84 \%, 93 \%$, and $100 \%$ to predict all OSA (apneahypopnea index $(\mathrm{AHI}) \geq 5)$, moderate-to-severe OSA $(\mathrm{AHI} \geq 15)$, and severe OSA (AHI $\geq 30$ ), respectively [20]. Due to its practicality and high sensitivity, the STOP-Bang questionnaire has been validated in surgical and sleep clinic settings worldwide; however, its validity has not been reviewed in two important populations relevant to primary care and public health, which are the general population and commercial driver population $[23,24]$. The objective of this systematic review and meta-analysis (SRMA) is to provide a comprehensive review of the predictive parameters of the STOP-Bang questionnaire in screening patients for OSA in the general population and commercial drivers. We hypothesize that the STOP-Bang questionnaire would be a useful armamentarium to screen for OSA in the general population and commercial drivers.

\section{Methods}

\section{Literature search and study selection}

The protocol of this SRMA was registered in the International Prospective Register of Systematic Reviews (PROSPERO) (CRD42020200379). We followed the Preferred Reporting Items for Systematic Reviews and Meta-analyses (PRISMA) guideline for this review [25]. A medical information specialist with expertise in systematic reviews (ME) designed and implemented the search strategy. The following databases were searched from January 2008 to March 2020 without language restrictions: MEDLINE, Medline-in-process, Embase, EmCare Nursing, Cochrane Central Register of Controlled Trials, Cochrane Database of Systematic Reviews, PsycINFO, Journals @ Ovid with full-text searching, all using the Ovid search interface; Web of Science (Clarivate Analytics), Scopus (Elsevier), and CINAHL. The search strategy included free-text and index terms: "stop-bang" or "stopbang". A Web of Science citation search on the initial validation article for the STOP-Bang questionnaire was run to capture articles that cited it going forward in time [20]. Also, we performed a manual citation search to retrieve related articles and continued literature surveillance through August 2020. The full search strategies used are shown in Supplementary Digital Content (Supplementary Appendix 1).

\section{Selection of studies}

After duplicates were removed, four reviewers (AS, SI, LC, BP) independently screened the titles and abstracts of retrieved articles using Rayyan [26]. Once irrelevant studies were excluded, full-text publications that met the following criteria were assessed for inclusion: (1) STOP-Bang questionnaire was evaluated in adults (age $\geq 18$ years), in the general population or commercial drivers; (2) OSA diagnosis was validated against lab-PSG or HSAT, and (3) apneahypopnea index (AHI) or respiratory disturbance index (RDI) were used to define OSA and its severity. Studies with pediatric, veteran, and pregnant populations were excluded. Throughout this process, disagreements regarding inclusion of abstracts and full-text articles were resolved through discussion among the co-authors (LC, BP) and the senior author (FC).

\section{Data extraction and management}

Two authors (LC, BP) independently recorded data from included studies using a pre-designed data collection form. The STOP-Bang score $\geq 3$ was accepted as the threshold, and studies that only analyzed predictive parameters at other STOP-Bang thresholds were excluded. OSA was defined as AHI of $\geq 5$ events per hour of sleep. Individuals with $\mathrm{AHI} \geq 15$ or $\mathrm{RDI} \geq 15$, and $\mathrm{AHI} \geq 30$ or $\mathrm{RDI} \geq 30$ were defined as having moderate-to-severe and severe OSA, respectively.

Predictive parameters reported at each AHI or RDI cutoff were used to compose a $2 \times 2$ contingency table for each study. If there was insufficient information to complete such table or if the study modified the STOP-Bang questionnaire, it was excluded. 


\section{Assessment of methodological quality}

Two reviewers (LC, BP) separately appraised the quality of included studies based on internal and external validity criteria described by the Cochrane Methods group on screening and diagnostic tests [27]. In the case of any disagreements, consensus was reached with a third reviewer (MN). We assessed internal validity through the following criteria: valid reference test, definition of disease, blind execution of the STOP-Bang questionnaire, independent interpretation of index test results from clinical information, and study design. We evaluated external validity using the following factors: disease spectrum, research setting, pre-screening or referral, availability of demographic information, explicit threshold of STOP-Bang, percentage of missing subjects, missing data management, and subject selection for PSG.

\section{Statistical analysis}

By creating $2 \times 2$ contingency tables, the following paired and unpaired predictive parameters were recalculated with $95 \%$ confidence interval (CI): prevalence, sensitivity and specificity; positive predictive value (PPV) and negative predictive value (NPV); and diagnostic odds ratio (DOR). The area under the summary receiver operating characteristic curves (AUC) were calculated using logistic regression. We grouped studies according to the type of population (general population or commercial drivers) and the AHI cutoffs with reported validity parameters. We recalculated the pooled predictive parameters at each AHI severity cutoff, and composed forest plots with a random-effects model. To analyze the diagnostic accuracy of the STOP-Bang questionnaire, we performed AUC analysis. Heterogeneity or inconsistency was quantified using the chi-squared $\left(\mathrm{chi}^{2}\right.$ or $X^{2}$ ) test ( $p$ value $<0.05$ : heterogeneity present) and $I^{2}$ test $\left(I^{2}>33 \%\right.$ : heterogeneity present). Analyses were performed using Review Manager Version 5.4 Copenhagen (The Nordic Cochrane Centre, The Cochrane Collaboration, 2020) and MetaDisc Version 1.4 (Hospital Ramony Cajal, Madrid, Spain).

\section{Results}

\section{Search results and selection process}

Figure 1 showcases our literature search strategy, which initially yielded 3871 citations. We found six potentially relevant studies by citation search. Following removal of duplicates, 2285 studies were evaluated. After title and abstract screening, 2267 studies were excluded because predetermined eligibility criteria were not met. From the remaining 18 articles, we excluded 11 studies after full-text review for various reasons (Supplementary Table 1) [28-38]. Seven studies were included with a total of 8770 subjects: five in the general population $(n=8585)$ [39-43] and two in commercial drivers $(n=185)$ $[44,45]$. The included studies were performed in various countries: the USA [39], Switzerland [40], Singapore [41], Chile [42], Belgium [43], Turkey [44], and Serbia [45].
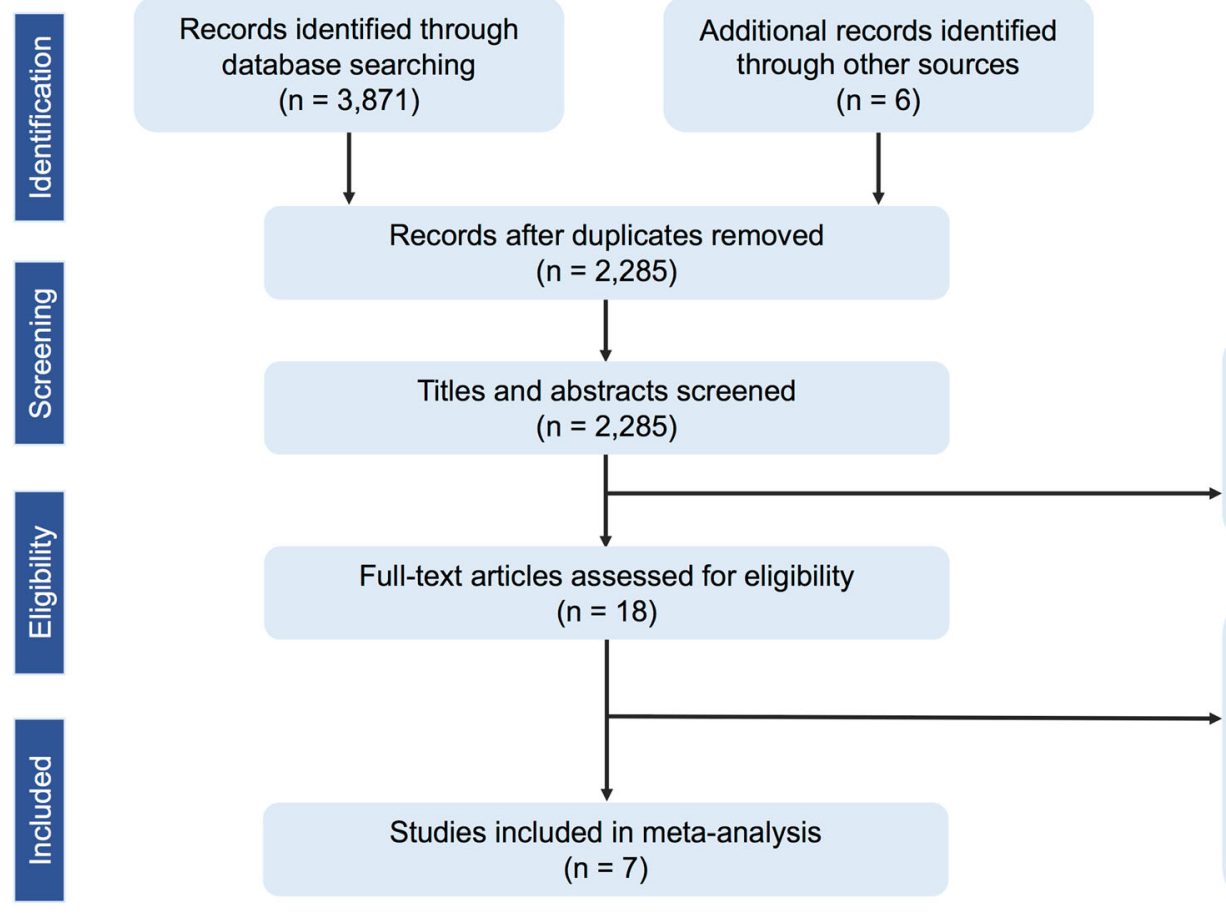

Records excluded $(n=2,267)$

Title screening $(n=1,985)$

Abstract screening $(n=265)$

Full texts not available $(n=17)$

Full-text articles excluded, with reasons below $(n=11)$

Wrong patient population $=5$ Wrong publication type $=1$ Use of modified STOP-Bang $=2$ Defined OSA by ODI $=1$ Different at-risk STOP-Bang cut-off than $\geq 3=2$

Fig. 1 Flow diagram of search strategy used for systematic review and meta-analysis. $O D I$, oxygen desaturation index 
From the general population, three studies $(n=3573)[40$, $42,43]$ were included for meta-analysis at $\mathrm{AHI} \geq 5$, five studies $(n=8586)$ [39-43] at AHI $\geq 15$, and four studies $(n=$ 8380) [39-41,43] at $\mathrm{AHI} \geq 30$. Among commercial drivers, one study $(n=100)$ [45] evaluated diagnostic accuracy at $\mathrm{AHI} \geq 5$, two $(\mathrm{n}=185)[44,45]$ at $\mathrm{AHI} \geq 15$, and one $(\mathrm{n}=$ 100) [45] at $\mathrm{AHI} \geq 30$.

\section{Quality assessment of included studies}

The results of internal and external validity assessment are presented in Supplementary Tables 2 and 3. With regard to internal validity, all selected studies used an accepted reference test to diagnose OSA and validate the STOP-Bang questionnaire. For blind execution of the index and reference tests, three studies were rated unclear risk of bias because they provided insufficient information as to whether the scoring of PSG readings and interpretation of STOP-Bang results were blinded. All seven studies had an unclear risk of bias regarding independent interpretation of the questionnaire to clinical information.

When evaluating external validity, all studies explicitly reported inclusion and exclusion criteria. Regarding prescreening before application of STOP-Bang scoring, three studies stratified their subjects into risk groups and then applied the questionnaire [41, 42, 45]. Finally, four studies provided incomplete information and analysis of missing data describing basic characteristics of those who were not included, lost to attrition, etc. [39, 41, 43, 44]. Overall, all the studies had low-to-moderate risk of bias and were considered acceptable to answer the review question.

\section{Characteristics of included studies}

The study characteristics and demographic data of the included studies are presented in Tables 1 and 2. Based on the available data, the general population had an average age of $60 \pm$ 11 years with a mean BMI of $27 \pm 5 \mathrm{~kg} / \mathrm{m}^{2}$ and $51 \%$ were male. In contrast, the commercial drivers group had a mean BMI of $29 \pm 5 \mathrm{~kg} / \mathrm{m}^{2}$ and all participants were male. There were variations in the cutoff criteria for OSA: five studies defined OSA using AHI $\geq 5[40-43,45]$, and two as either $\mathrm{AHI} \geq 15$ [44] or $\mathrm{RDI} \geq 15$ [39]. The $2 \times 2$ contingency tables and predictive parameters for individual studies are shown in Supplementary Table 4.

\section{Predictive parameters in the general population}

The distributions of the pooled predictive parameters for a STOP-Bang $\geq 3$ cutoff are summarized in Table 3 and Fig. 2. The prevalence of all OSA (AHI $\geq 5)$, moderate-tosevere OSA $(\mathrm{AHI} \geq 15)$, and severe $\mathrm{OSA}(\mathrm{AHI} \geq 30)$ was

Table 1 Characteristics of included studies in the general population and in commercial drivers

\begin{tabular}{|c|c|c|c|c|c|c|c|c|}
\hline Study ID & $\begin{array}{l}\text { Study } \\
\text { population } \\
\text { and sample } \\
\text { size }(n)\end{array}$ & $\begin{array}{l}\text { Study type and } \\
\text { validation tool }\end{array}$ & $\begin{array}{l}\text { OSA } \\
\text { Prevalence } \\
(\%)\end{array}$ & $\begin{array}{l}\text { OSA } \\
\text { definition }\end{array}$ & $\begin{array}{l}\text { No OSA } \\
\mathrm{AHI}<5 \\
n(\%)\end{array}$ & $\begin{array}{l}\text { Mild OSA } \\
\mathrm{AHI} \geq 5 \text { to } \mathrm{AHI}<15 \\
n(\%)\end{array}$ & $\begin{array}{l}\text { Moderate OSA } \\
\mathrm{AHI} \geq 15 \text { to } \mathrm{AHI}<30 \\
\mathrm{RDI} \geq 15 \text { to } \mathrm{RDI}<30 \\
n(\%)\end{array}$ & $\begin{array}{l}\text { Severe OSA } \\
\mathrm{AHI} \geq 30 \text { or } \mathrm{RDI} \geq 30 \\
n(\%)\end{array}$ \\
\hline \multicolumn{9}{|c|}{ General population } \\
\hline $\begin{array}{c}\text { Silva [39] } \\
2011\end{array}$ & American 4770 & $\begin{array}{l}\text { Retrospective HSAT } \\
\text { (Compumedics } \\
\text { Portable PS-2) }\end{array}$ & $19.9 \%$ & $\mathrm{RDI} \geq 15$ & NA & RDI $<15: 3822(80.1)$ & $603(12.7)$ & $345(7.2)$ \\
\hline $\begin{array}{l}\text { Marti-Soler } \\
{[40]} \\
2016\end{array}$ & Swiss 1559 & $\begin{array}{l}\text { Prospective HSAT } \\
\quad \text { (Titanium Embla) }\end{array}$ & $71.9 \%$ & $\mathrm{AHI} \geq 5$ & $438(28.1)$ & $570(36.6)$ & $333(21.3)$ & $218(14.0)$ \\
\hline $\begin{array}{c}\text { Tan [41] } \\
2016\end{array}$ & Singaporean 242 & $\begin{array}{l}\text { Prospective HSAT } \\
\text { (Embletta Gold) }\end{array}$ & $72.7 \%$ & $\mathrm{AHI} \geq 5$ & $66(27.3)$ & 108 (44.6) & $42(17.4)$ & $26(10.7)$ \\
\hline $\begin{array}{l}\text { Saldías } \\
\quad \text { Peñafiel } \\
{[42]} \\
2019\end{array}$ & Chilean 205 & $\begin{array}{l}\text { Cross-sectional HSAT } \\
\text { (NA) }\end{array}$ & $59.0 \%$ & $\mathrm{AHI} \geq 5$ & $84(41.0)$ & $67(32.7)$ & $33(16.1)$ & $21(10.2)$ \\
\hline $\begin{array}{l}\text { Bauters [43] } \\
2020\end{array}$ & Belgian 1809 & $\begin{array}{l}\text { Prospective HSAT } \\
\text { (ApneaLink) }\end{array}$ & $45.1 \%$ & $\mathrm{AHI} \geq 5$ & 993 (54.9) & 604 (33.4) & $145(8.0)$ & $67(3.7)$ \\
\hline \multicolumn{9}{|c|}{ Commercial drivers } \\
\hline $\begin{array}{c}\text { Firat [44] } \\
\quad 2012\end{array}$ & Turkish 85 & $\begin{array}{l}\text { Cross-sectional lab } \\
\text { PSG }\end{array}$ & $54.1 \%$ & AHI $>15$ & NA & AHI<15: $39(46.9)$ & $46(54.1)$ & NA \\
\hline $\begin{array}{c}\text { Popević } \\
{[45]} \\
2017\end{array}$ & Serbian 100 & $\begin{array}{l}\text { Prospective lab PSG } \\
\text { lab (type III) }\end{array}$ & $57.0 \%$ & $\mathrm{AHI} \geq 5$ & $43(43.0)$ & $34(34.0)$ & $11(11.0)$ & $12(12.0)$ \\
\hline
\end{tabular}

AHI apnea-hypopnea index, HSAT home sleep apnea testing, Lab laboratory, NA not available, OSA obstructive sleep apnea, $P S G$ polysomnography, $R D I$ respiratory desaturation index 
Table 2 Demographic data of individuals in the general population and in commercial drivers ${ }^{\mathrm{a}}$

\begin{tabular}{|c|c|c|c|c|c|c|c|c|}
\hline Study ID & $\begin{array}{l}\text { No. of } \\
\text { patients }\end{array}$ & $\begin{array}{l}\text { Age } \\
\text { (year) }\end{array}$ & $\begin{array}{l}\text { Male } \\
(\%)\end{array}$ & $\begin{array}{l}\mathrm{BMI}(\mathrm{kg} / \\
\left.\mathrm{m}^{2}\right)\end{array}$ & $\begin{array}{l}\text { Neck circumference } \\
(\mathrm{cm})\end{array}$ & $\begin{array}{l}\text { STOP-Bang } \\
\text { Score }\end{array}$ & $\begin{array}{l}\mathrm{AHI} / \\
\mathrm{RDI}\end{array}$ & $\begin{array}{l}\text { Minimum } \mathrm{SpO}_{2} \\
(\%)\end{array}$ \\
\hline \multicolumn{9}{|l|}{ General population } \\
\hline Silva [39] 2011 & 4770 & $62 \pm 10$ & 52 & NA & NA & $3.4 \pm 1$ & NA & NA \\
\hline Marti-Soler [40] 2016 & $\begin{array}{l}2121 \\
1559^{\dagger}\end{array}$ & $59 \pm 11$ & 48 & $26 \pm 4$ & $36.9 \pm 4$ & NA & NA & NA \\
\hline Tan [41] 2016 & 242 & $48 \pm 14$ & 50 & $26 \pm 5$ & $36.4 \pm 4$ & $2 \pm 2$ & $14 \pm 14$ & $83.5 \pm 7$ \\
\hline $\begin{array}{l}\text { Saldías Peñafiel [42] } \\
2019\end{array}$ & 205 & $51 \pm 15$ & 46 & $29 \pm 5$ & $37.9 \pm 4$ & NA & NA & NA \\
\hline Bauters [43] 2020 & 1809 & $56 \pm 6$ & 48 & $27 \pm 5$ & $37.5 \pm 4$ & $2 \pm 2$ & NA & NA \\
\hline \multicolumn{9}{|l|}{ Commercial drivers } \\
\hline Firat [44] 2012 & 85 & NA & 100 & $29 \pm 4$ & $41.1 \pm 3$ & NA & $21 \pm 17$ & NA \\
\hline Popević [45] 2017 & 100 & $43 \pm 11$ & 100 & $29 \pm 6$ & $40.4 \pm 3$ & NA & $12 \pm 15$ & NA \\
\hline
\end{tabular}

$A H I$ apnea-hypopnea index, $N A$ not available, $R D I$ respiratory desaturation index

${ }^{a}$ Data are presented as mean \pm SD when appropriate

${ }^{\mathrm{b}}$ Demographic data was reported for 2121 total participants who underwent PSG, but STOP-Bang was validated in 1559 of 2121 individuals

$57.6 \%, 21.3 \%$, and $7.8 \%$ respectively. A STOP-Bang score 3 or greater for an AHI cutoff $\geq 15$ and 30 had excellent pooled sensitivities of $88 \%$ (95\% CI: $86-89 \%$ ) and $92 \%$ (95\% CI: 89-94\%), respectively. The STOP-Bang $\geq 3$ also had high discriminative power to exclude moderate-to-severe and severe OSA as reflected by pooled NPVs $(93 \%$ (95\% CI: 92 94\%) and 98\% (95\%CI: 98-99\%), respectively). For the detection of all OSA at AHI $\geq 5$, a STOP-Bang score $\geq 3$ had moderate sensitivity (73\%; 95\% CI: 71-75\%) and modest specificity $(66 \%$; 95\%CI: 63-68\%). The DOR increased with
OSA severity and ranged from 4.5 (95\%CI: 3.2-6.2) to 6.6 (95\%CI: 4.3-10.3). The AUC was consistently $>0.73$ for different severities of OSA with the highest for moderate-tosevere OSA at 0.76 (95\% CI: $0.72-0.80$ ).

\section{Predictive parameters in commercial drivers}

In the commercial driver population, the prevalence of OSA for moderate-to-severe OSA was $37.3 \%$. At this severity, a STOP-Bang score $\geq 3$ shows excellent pooled sensitivity at
Table 3 Pooled predictive parameters of STOP-Bang $\geq 3$ as thresholds ${ }^{\mathrm{a}}$

\begin{tabular}{llll}
\hline $\begin{array}{l}\text { Predictive parameters } \\
(95 \% \text { CI })\end{array}$ & All OSA (AHI $\geq 5)$ & $\begin{array}{l}\text { Moderate-to-severe } \\
\text { OSA (AHI } \geq 15)\end{array}$ & Severe OSA (AHI $\geq 30)$ \\
\hline General population & 3 studies; $n=3573$ & 5 studies; $n=8586$ & 4 studies; $n=8380$ \\
Prevalence & $57(56-59)$ & $21(20-22)$ & $8(7-8)$ \\
Sensitivity & $73(71-75)$ & $88(86-89)$ & $92(89-94)$ \\
Specificity & $66(63-68)$ & $42(40-43)$ & $38(37-39)$ \\
PPV & $74(72-76)$ & $29(28-30)$ & $11(10-12)$ \\
NPV & $64(62-67)$ & $93(92-94)$ & $98(98-99)$ \\
DOR & $4.5(3.2-6.2)$ & $5.3(4.1-6.9)$ & $6.6(4.3-10.3)$ \\
AUC & $0.73(0.71-0.75)$ & $0.76(0.72-0.80)$ & $0.74(0.72-0.76)$ \\
Commercial drivers & 1 study; $n=100$ & 2 studies; $n=185$ & 1 study; $n=100$ \\
Prevalence & - & $37(30-44)$ & - \\
Sensitivity & - & $91(82-97)$ & - \\
Specificity & - & $43(34-53)$ & - \\
PPV & - & $49(40-58)$ & - \\
NPV & - & $89(77-95)$ & - \\
DOR & - & $9(2.1-37.6)$ & - \\
\hline
\end{tabular}

$O R$ odds ratio, $C I$ confidence interval, $A U C$ area under summary of receiver operating characteristic curve

${ }^{a}$ Data are expressed as percentage and $95 \%$ confidence interval 


\section{All OSA (AHI $\geq 5)$ - General Population}

Study

Bauters 2020

Marti-Soler 2016

Saldias Penafiel 2019 $\begin{array}{llll}\text { TP FP } & \text { FN TN }\end{array}$

$\begin{array}{llll}503 & 293 & 313 & 700\end{array}$

$\begin{array}{llll}897 & 179 & 224 & 259\end{array}$

$\begin{array}{llll}99 & 46 & 22 & 38\end{array}$
$0.62[0.58,0.65]$
$0.80[0.78,0.82]$

$0.80[0.78,0.82]$

$0.82[0.74,0.88]$
Specificity $(95 \% \mathrm{Cl})$

$0.70[0.68,0.73]$

$0.59[0.54,0.64]$

$0.45[0.34,0.56]$
Sensitivity $(95 \% \mathrm{Cl}) \quad$ Specificity $(95 \% \mathrm{Cl})$

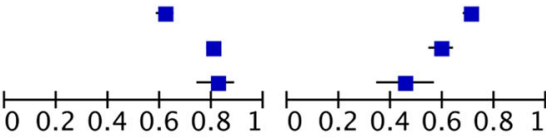

Pooled Sensitivity = $0.73(0.71-75)$; Chi-squared = 84.65; df = 2 ( $p=0.000)$; Inconsistency $(\mathrm{I}-\mathrm{square})=97.6 \%$

Pooled Specificity = $0.66(0.63-0.68) ;$ Chi-Squared = 33.21; $\mathrm{df}=2(\mathrm{p}=0.000)$; Inconsistency $(\mathrm{I}-\mathrm{square})=94.0 \%$

\section{Moderate-to-Severe OSA (AHI $\geq 15)$ - General Population}

Study

Bauters 2020

Marti-Soler 2016

Saldias Penafiel 2019

Silva 2011

Tan 2016

$\begin{array}{rrrr}\text { TP } & \text { FP } & \text { FN } & \text { TN } \\ 162 & 634 & 50 & 963 \\ 501 & 575 & 50 & 434 \\ 48 & 97 & 6 & 54 \\ 853 & 2600 & 95 & 1222 \\ 45 & 44 & 23 & 130\end{array}$

$0.76[0.70,0.82]$

$0.91[0.88,0.93]$

$0.89[0.77,0.96]$

$0.90[0.88,0.92]$

$0.66[0.54,0.77]$
Specificity $(95 \% \mathrm{Cl})$

$0.60[0.58,0.63]$

$0.43[0.40,0.46]$

$0.36[0.28,0.44]$

$0.32[0.30,0.33]$

$0.75[0.68,0.81]$
Sensitivity $(95 \% \mathrm{CI}) \quad$ Specificity $(95 \% \mathrm{Cl})$

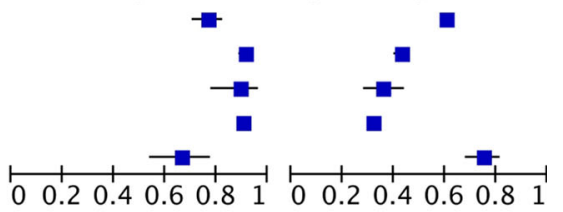

Pooled Sensitivity = $0.88(0.86-0.89)$; Chi-squared $=52.33 ; \mathrm{df}=4(\mathrm{p}=0.000)$; Inconsistency (l-square $)=92.4 \%$

Pooled Specificity = $0.42(0.40-0.43)$; Chi-Squared $=457.31 ; \mathrm{df}=4(\mathrm{p}=0.000)$; Inconsistency $(\mathrm{l}$-square $)=99.1 \%$

\section{Severe OSA (AHI $\geq 30)$ - General Population}

\begin{tabular}{|c|c|c|c|c|c|c|c|c|}
\hline Study & TP & FP & FN & TN & Sensitivity $(95 \% \mathrm{CI})$ & Specificity $(95 \% \mathrm{CI})$ & Sensitivity $(95 \% \mathrm{CI})$ & Specificity $(95 \% \mathrm{Cl})$ \\
\hline Bauters 2020 & 56 & 740 & 11 & 1002 & $0.84[0.73,0.92]$ & $0.58[0.55,0.60]$ & $\rightarrow$ & घ \\
\hline Marti-Soler 2016 & 209 & 867 & 9 & 474 & $0.96[0.92,0.98]$ & $0.35[0.33,0.38]$ & 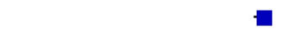 & - \\
\hline Silva 2011 & 319 & 3134 & 26 & 1291 & $0.92[0.89,0.95]$ & $0.29[0.28,0.31]$ & - & - \\
\hline Tan 2016 & 18 & 71 & 8 & 145 & $0.69[0.48,0.86]$ & $0.67[0.60,0.73]$ & $\frac{1}{1}$ & + \\
\hline
\end{tabular}

Pooled Sensitivity = $0.92(0.89-0.94) ;$ Chi-squared = 21.76; df = 3 (p=0.000); Inconsistency (I-square) = 86.2\%

Pooled Specificity = $0.38(0.37-0.39) ;$ Chi-Squared = 501.60; df = 3 (p=0.000); Inconsistency (l-square) = 99.4\%

\section{Moderate-to-Severe OSA (AHI $\geq 15)$ - Commercial Drivers}

\begin{tabular}{|c|c|c|c|c|c|c|c|c|}
\hline Study & TP & FP & FN & TN & Sensitivity $(95 \% \mathrm{CI})$ & Specificity (95\% CI) & Sensitivity $(95 \% \mathrm{CI})$ & Specificity (95\% Cl) \\
\hline Firat 2012 & 40 & 20 & 6 & 19 & $0.87[0.74,0.95]$ & $0.49[0.32,0.65]$ & & $\longrightarrow$ \\
\hline Popevic 2017 & 23 & 46 & 0 & 31 & $1.00[0.85,1.00]$ & $0.40[0.29,0.52]$ & & \\
\hline
\end{tabular}

Pooled Sensitivity = $0.91(0.82-0.97) ;$ Chi-squared $=5.15 ; \mathrm{df}=1(\mathrm{p}=0.023)$; Inconsistency $(\mathrm{I}-\mathrm{square})=80.6 \%$

Pooled Specificity = $0.43(0.34-0.53) ;$ Chi-Squared $=0.75 ; \mathrm{df}=1(p=0.386) ;$ Inconsistency $(\mathrm{l}-\mathrm{square})=0 \%$

Fig. 2 Forest plot for pooled sensitivity and specificity for various OSA severities in the general population and for moderate-to-severe OSA in commercial drivers. $T P$, true positive; $F P$, false positive; $F N$, false negative; $T N$, true negative; $C I$, confidence interval

91\% (95\%CI: 82-97\%) and pooled NPV at 89\% (95\%CI: 77$95 \%)$. The associated pooled specificity was $43 \%$ (95\% CI: 34-53\%) and PPV was 49\% (95\%CI: 40-58\%) (Fig. 2,
Table 3). The DOR was 9 (95\%CI: 2.1-37.6) and an AUC curve could not be produced because of limited available studies. 


\section{Discussion}

This SRMA demonstrates that the STOP-Bang questionnaire is a valid screening tool in the general population and commercial drivers. The high sensitivity of a STOP-Bang score $\geq$ 3 , ranging from 88 to $92 \%$, helps to identify those in the community and commercial drivers who are at risk for moderate-to-severe and severe OSA. In the general population with a STOP-Bang score of $0-2$, the high negative predictive values of $93 \%$ and $98 \%$ of a STOP-Bang score $\geq 3$ means that we will be confident to rule out moderate-to-severe OSA and severe OSA. Similarly, the high NPV in commercial drivers of $89 \%$ also indicates that those with a STOP-Bang score of 0-2 have a low probability of having moderate-to-severe OSA. In the general population, the AUC is clinically significant (> 0.73 ) at each AHI threshold signifying the diagnostic utility of the STOP-Bang questionnaire. This trend in sensitivities and NPV is similar to STOP-Bang performance in different populations, such as the sleep clinic and surgical population [23].

There is usually a trade-off between the sensitivity and specificity of a screening tool so that the high sensitivity of the STOP-Bang questionnaire comes at the cost of high specificity. In this study, a STOP-Bang score $\geq 3$ has relatively low to moderate specificity across all OSA severities and in both populations. This modest specificity may subject individuals to false-positive results, which leads to unnecessary PSG or HSAT testing. Nonetheless, minimizing false positives is of secondary importance when compared to the disease burden, safety hazard, and relatively higher cost of missed OSA cases $[24,46]$. While the risk of further investigation if identified as positive by the STOP-Bang questionnaire is low, the risks associated with undiagnosed sleep apnea are dire [10-16, $18,47]$. For OSA, high sensitivity is clinically relevant as it enhances the early diagnosis of those with unrecognized OSA. Alternatively, a higher cutoff can be utilized which will increase specificity but lower sensitivity [21, 22]. Also, the STOP-Bang questionnaire can be used together with the Epworth Sleepiness Scale to increase specificity if needed [35].

\section{Application of the STOP-Bang questionnaire in the general population}

We found a higher prevalence of OSA ( $58 \%$ at $\mathrm{AHI} \geq 5)$ than past estimates [3]. This possible overestimation may be due to biased sampling methods from the general population. Silva et al. included older participants indirectly assembled from multiple longitudinal community-based cohorts [39], and Tan et al. used a sample of all snoring subjects and a subsample of non-snoring subjects from its existing populationbased cohort [41]. Also, the high prevalence may be due to the increasing obesity epidemic, a strong risk factor for OSA [1, 48]. In addition, the changes in measurement techniques and scoring criteria for OSA may contribute to the higher prevalence of OSA $[1,48]$. By using more recent OSA diagnosis criteria by the American Academy of Sleep Medicine, researchers have found prevalence of OSA which is comparable to the prevalence in our included studies [2].

For $\mathrm{AHI} \geq 5$ with high prevalence, the STOP-Bang questionnaire has moderate sensitivity and specificity at $73 \%$ and $66 \%$, respectively. While AHI $\geq 5$ is applicable for research purposes, this cutoff for mild-to-severe OSA is neither clinically significant nor strongly associated with adverse comorbidities [17]. Thus, we recommend the utilization of STOPBang questionnaire for its discriminative power for moderateto-severe and severe OSA.

Often, primary care physicians have sufficient knowledge about OSA but fail to screen and manage their patients [49, 50]. Approximately $50 \%$ of general practitioners did not screen those at high risk for OSA, and 90\% did not use OSA screening tools [51]. In general, the public has limited awareness of the presence of OSA and its devastating consequences $[52,53]$. As many are asymptomatic and do not experience subjective sleepiness or impaired objective vigilance [54], individuals with undiagnosed OSA do not self-recognize their symptoms. Importantly, AHI does not necessarily correlate with extent of symptoms [55], which furthers the need for efficient screening and diagnosis. If primary care physicians suspect OSA, the STOP-Bang questionnaire helps with risk stratification and proper triage for appropriate care of OSA [56]. It reduces referral to overwhelmed sleep clinics with long wait times and is a feasible implementation process given the simplicity and short administration time of the questionnaire [57].

The American Academy of Sleep Medicine Clinical Practice Guidelines for diagnostic testing for OSA in adults recommended against the use of clinical tools, questionnaires, and prediction algorithms for the diagnosis of OSA [58]. The STOP-Bang questionnaire fulfills the unmet need for a screening test that effectively detects or rules out possible OSA in the community, and thus can save healthcare costs upstream of potential harms related to OSA. Its purpose is not to replace the PSG or HSAT.

\section{Utility of the STOP-Bang questionnaire in commercial drivers}

Commercial drivers are mostly male, obese, and sedentary for extended periods of time, which are all significant risk factors for OSA [59, 60]. In this SRMA, the subjects were overweight with BMI $<30 \mathrm{~kg} / \mathrm{m}^{2}$. The recent Canadian Clinical Guidelines on obesity in adults emphasize that obesity should be defined by how it impacts a person's health as a chronic disease rather than by a misleading value such as BMI [48]. Furthermore, a bidirectional relationship exists between metabolic syndrome in male drivers and the presence of OSA [61]. These 
associations highlight the importance of screening commercial drivers for OSA, considering their potential comorbidities.

In occupations that require a high level of alertness, excessive daytime sleepiness caused by OSA poses serious risks for injuries and fatalities [62]. A study in heavy equipment operators found that higher AHI with sleepiness was significantly linked to more accidents [63]. Comparably in commercial airline pilots, nearly one-third of pilots were at high risk of OSA with half falling asleep without notifying their co-pilot $[63,64]$. Untreated commercial drivers with severe OSA have a significantly increased risk of near-miss accidents and motor-vehicle accidents $[19,65]$. For the safety of commercial drivers and those who share the road with them, it is imperative that commercial drivers be screened for OSA during medical examinations for their certification and at periodic intervals afterwards. In the USA, the Federal Motor Carrier Safety Administration (FMCSA) has yet to recommend the use of validated screening tools over traditional questioning by medical examiners [29, 66]. Commercial drivers may not be aware of OSA symptoms or may be reluctant to self-report OSA for reasonable fear of losing their licenses and experiencing financial hardship [19]. With its subjective and objective questions, the STOP-Bang questionnaire has a potential role in occupational clinical settings [60]. The STOP-Bang questionnaire rules out moderate-to-severe OSA confidently in commercial drivers who are considered low-risk by the questionnaire. Due to the limited studies, further research is recommended.

\section{Limitations}

Our SRMA has some limitations. First, the studies in commercial drivers had small sample sizes which may have produced imprecise pooled predictive parameters with wide confidence intervals. Only male drivers were studied, so the results may not be applicable to female drivers. Second, the risk of bias in some studies remained unclear, and selection bias in the general population studies may have compromised external validity of the meta-analysis. Third, the inconsistency $\left(\mathrm{I}^{2}\right)$ of the predictive parameters is consistently high presumably due to methodological heterogeneity. Another reason for the heterogeneity could be the variability in prevalence of OSA across the different populations and countries. Since heterogeneity was suspected, we used a random-effects model for meta-analysis. The attempted meta-regression analysis to explore the heterogeneity was not possible due to the limited number of studies in the meta-analysis. Fourth, our statistical method did not address the overestimation of overall diagnostic test accuracy resulting from the interpretation of each outcome measure individually. Hierarchical models, such as the bivariate random-effects model, could account for this limitation if there are more studies available for meta-analysis. Finally, all studies in the general population used HSAT as their reference test. Although HSAT is an accepted test for diagnosing OSA, there is uncertainty surrounding the time spent asleep which could lead to an underestimation of AHI [67]. Given the difficulty of administering PSG to the general population, we consider HSAT a reasonable reference test, especially since conducting the recording in the participant's home can reduce information bias. Despite these limitations, our SRMA delivers an important interpretation of the available literature on STOP-Bang questionnaire in the general population and commercial drivers.

\section{Conclusions}

In conclusion, this meta-analysis demonstrates that the STOPBang questionnaire has been validated to be a fast and easy-touse screening tool for the general population and commercial drivers. At a score of 3 or greater, the STOP-Bang questionnaire performs with high sensitivity and NPV. Thus, primary care physicians and occupational safety examiners can confidently rule out clinically relevant OSA in their respective populations. From a public health perspective, wider use of the STOP-Bang questionnaire to screen for OSA helps improve public health and reduce safety risks caused by sleep apnea in the general population and especially in commercial drivers.

Supplementary Information The online version contains supplementary material available at https://doi.org/10.1007/s11325-021-02299-y.

Acknowledgements The authors thank Rida Waseem, MA Toronto Western Hospital, University Health Network, University of Toronto, Canada, for her assistance with the literature search.

Author contribution FC guarantees the integrity of the work; MN and FC contributed to the conception and design of the study; LC, BP, MN, AP, SI, ME, and FC contributed to the literature search, data extraction, and quality assessment; LC, MN, and FC contributed to data analysis and writing of the manuscript. All authors approved the manuscript.

Data availability Not applicable.

\section{Declarations}

Ethics approval and consent to participate Not applicable.

Consent for publication Not applicable.

Competing interests Frances Chung - Up-to-Date royalties, STOPBang questionnaire (proprietary to University Health Network). The other authors declare no competing interests.

Code availability Not applicable.

Open Access This article is licensed under a Creative Commons Attribution 4.0 International License, which permits use, sharing, adaptation, distribution and reproduction in any medium or format, as long as you give appropriate credit to the original author(s) and the source, provide a link to the Creative Commons licence, and indicate if changes were made. The images or other third party material in this article 
are included in the article's Creative Commons licence, unless indicated otherwise in a credit line to the material. If material is not included in the article's Creative Commons licence and your intended use is not permitted by statutory regulation or exceeds the permitted use, you will need to obtain permission directly from the copyright holder. To view a copy of this licence, visit http://creativecommons.org/licenses/by/4.0/.

\section{References}

1. Peppard PE, Young T, Barnet JH, Palta M, Hagen EW, Hla KM (2013) Increased prevalence of sleep-disordered breathing in adults. Am J Epidemiol 177(9):1006-1014. https://doi.org/10.1093/aje/ kws 342

2. Heinzer R, Vat S, Marques-Vidal P, Marti-Soler H, Andries D, Tobback N, Mooser V, Preisig M, Malhotra A, Waeber G, Vollenweider P, Tafti M, Haba-Rubio J (2015) Prevalence of sleep-disordered breathing in the general population: the HypnoLaus study. Lancet Respir Med 3(4):310-318. https://doi. org/10.1016/S2213-2600(15)00043-0

3. Senaratna CV, Perret JL, Lodge CJ, Lowe AJ, Campbell BE, Matheson MC, Hamilton GS, Dharmage SC (2017) Prevalence of obstructive sleep apnea in the general population: a systematic review. Sleep Med Rev 34:70-81. https://doi.org/10.1016/j.smrv. 2016.07.002

4. Tufik S, Santos-Silva R, Taddei JA, Bittencourt LRA (2010) Obstructive sleep apnea syndrome in the Sao Paulo epidemiologic sleep study. Sleep Med 11(5):441-446. https://doi.org/10.1016/j. sleep.2009.10.005

5. Reddy EV, Kadhiravan T, Mishra HK, Sreenivas V, Handa KK, Sinha S, Sharma SK (2009) Prevalence and risk factors of obstructive sleep apnea among middle-aged urban Indians: a communitybased study. Sleep Med 10(8):913-918. https://doi.org/10.1016/j. sleep.2008.08.011

6. Redline S, Sotres-Alvarez D, Loredo J, Hall M, Patel SR, Ramos A, Shah N, Ries A, Arens R, Barnhart J, Youngblood M, Zee P, Daviglus ML (2014) Sleep-disordered breathing in Hispanic/ Latino individuals of diverse backgrounds. The Hispanic Community Health Study/Study of Latinos. Am J Respir Crit Care Med 189(3):335-344. https://doi.org/10.1164/rccm.201309$1735 \mathrm{OC}$

7. Young T, Evans L, Finn L, Palta M (1997) Estimation of the clinically diagnosed proportion of sleep apnea syndrome in middleaged men and women. Sleep. 20(9):705-706. https://doi.org/10. 1093/sleep/20.9.705

8. Berger M, Varvarigou V, Rielly A, Czeisler CA, Malhotra A, Kales SN (2012) Employer-mandated sleep apnea screening and diagnosis in commercial drivers. J Occup Environ Med 54(8):1017-1025. https://doi.org/10.1097/JOM.0b013e3182572e16

9. Gurubhagavatula I, Maislin G, Nkwuo JE, Pack AI (2004) Occupational screening for obstructive sleep apnea in commercial drivers. Am J Respir Crit Care Med 170(4):371-376. https://doi. org/10.1164/rccm.200307-968OC

10. Marin JM, Agusti A, Villar I, Forner M, Nieto D, Carrizo SJ, Barbé F, Vicente E, Wei Y, Nieto FJ, Jelic S (2012) Association between treated and untreated obstructive sleep apnea and risk of hypertension. JAMA. 307(20):2169-2176. https://doi.org/10.1001/jama. 2012.3418

11. Redline S, Yenokyan G, Gottlieb DJ, Shahar E, O'Connor GT, Resnick HE, Diener-West M, Sanders MH, Wolf PA, Geraghty EM, Ali T, Lebowitz M, Punjabi NM (2010) Obstructive sleep apnea-hypopnea and incident stroke: the sleep heart health study.
Am J Respir Crit Care Med 182(2):269-277. https://doi.org/10. 1164/rccm.200911-1746OC

12. Hla KM, Young T, Hagen EW, Stein JH, Finn LA, Nieto FJ, Peppard PE (2015) Coronary heart disease incidence in sleep disordered breathing: the Wisconsin Sleep Cohort Study. Sleep. 38(5): 677-684. https://doi.org/10.5665/sleep.4654

13. Yaffe K, Laffan AM, Harrison SL, Redline S, Spira AP, Ensrud KE, Ancoli-Israel S, Stone KL (2011) Sleep-disordered breathing, hypoxia, and risk of mild cognitive impairment and dementia in older women. JAMA. 306(6):613-619. https://doi.org/10.1001/ jama.2011.1115

14. Lang CJ, Appleton SL, Vakulin A, McEvoy RD, Vincent AD, Wittert GA et al (2017) Associations of undiagnosed obstructive sleep apnea and excessive daytime sleepiness with depression: an Australian population study. J Clin Sleep Med 13(4):575-582. https://doi.org/10.5664/jcsm.6546

15. Young T, Finn L, Peppard PE, Szklo-Coxe M, Austin D, Nieto FJ et al (2008) Sleep disordered breathing and mortality: eighteen-year follow-up of the Wisconsin sleep cohort. Sleep. 31(8):1071-1078

16. Punjabi NM, Caffo BS, Goodwin JL, Gottlieb DJ, Newman AB, O'Connor GT et al (2009) Sleep-disordered breathing and mortality: a prospective cohort study. PLoS Med 6(8):e1000132-e. https:// doi.org/10.1371/journal.pmed.1000132

17. Marshall NS, Wong KKH, Cullen SRJ, Knuiman MW, Grunstein RR (2014) Sleep apnea and 20-year follow-up for all-cause mortality, stroke, and cancer incidence and mortality in the Busselton Health Study Cohort. J Clin Sleep Med 10(04):355-362. https:// doi.org/10.5664/jcsm.3600

18. Gottlieb DJ, Ellenbogen JM, Bianchi MT, Czeisler CA (2018) Sleep deficiency and motor vehicle crash risk in the general population: a prospective cohort study. BMC Med 16(1):44. https://doi. org/10.1186/s12916-018-1025-7

19. Kales SN, Straubel MG (2014) Obstructive sleep apnea in North American commercial drivers. Ind Health 52(1):13-24. https://doi. org/10.2486/indhealth.2013-0206

20. Chung F, Yegneswaran B, Liao P, Sharon C, Vairavanathan S, Islam S et al (2008) STOP Questionnaire: a tool to screen patients for obstructive sleep apnea. Anesthesiology: The Journal of the American Society of Anesthesiologists 108(5):812-821. https:// doi.org/10.1097/ALN.0b013e31816d83e4

21. Chung F, Abdullah HR, Liao P (2016) STOP-Bang questionnaire: a practical approach to screen for obstructive sleep apnea. CHEST. 149(3):631-638. https://doi.org/10.1378/chest.15-0903

22. Chung F, Subramanyam R, Liao P, Sasaki E, Shapiro C, Sun Y (2012) High STOP-Bang score indicates a high probability of obstructive sleep apnoea. Br J Anaesth 108(5):768-775. https://doi. org $/ 10.1093 / \mathrm{bja} /$ aes022

23. Nagappa M, Liao P, Wong J, Auckley D, Ramachandran SK, Memtsoudis S, Mokhlesi B, Chung F (2015) Validation of the STOP-Bang questionnaire as a screening tool for obstructive sleep apnea among different populations: a systematic review and metaanalysis. PLoS One 10(12):21. https://doi.org/10.1371/journal. pone. 0143697

24. Chiu HY, Chen PY, Chuang LP, Chen NH, Tu YK, Hsieh YJ, Wang YC, Guilleminault C (2017) Diagnostic accuracy of the Berlin questionnaire, STOP-BANG, STOP, and Epworth sleepiness scale in detecting obstructive sleep apnea: a bivariate metaanalysis. Sleep Med Rev 36:57-70. https://doi.org/10.1016/j.smrv. 2016.10.004

25. Moher D, Liberati A, Tetzlaff J, Altman DG, The PG (2009) Preferred reporting items for systematic reviews and meta-analyses: the PRISMA statement. PLoS Med 6(7):e1000097. https://doi.org/ 10.1371/journal.pmed.1000097

26. Ouzzani M, Hammady H, Fedorowicz Z, Elmagarmid A. Rayyan - a web and mobile app for systematic reviews. . Syst Rev 2016; 5 5(210). https://doi.org/10.1186/s13643-016-0384-4 
27. Cochrane methods group on screening and diagnostic tests. [cited 2020 Aug 18]. Available from: http://srdta.cochrane.org/

28. Cruces-Artero C, Herves-Beloso C, Martin-Miguel V, HernaizValero S, Lago-Deibe FI, Montero-Gumucio M et al (2019) Diagnostic accuracy of STOP-Bang questionnaire on moderate sleep apnoea in primary care. Gac Sanit 33(5):421-426. https:// doi.org/10.1016/j.gaceta.2018.05.003

29. Evans KA, Yap T, Turner B (2017) Screening commercial vehicle drivers for obstructive sleep apnea: tools, barriers, and recommendations. Workplace Health \& Safety 65(10):487-492. https://doi. org $/ 10.1177 / 2165079917692597$

30. Jeon HJ, Bang YR, Yoon IY (2019) A validation study on three screening questionnaires for obstructive sleep apnea in a Korean community sample. Sleep Breath 23(3):969-977. https://doi.org/ 10.1007/s11325-018-1748-x

31. Martins EF, Martinez D, Cortes AL, Nascimento N, Brendler J (2020) Exploring the STOP-BANG questionnaire for obstructive sleep apnea screening in seniors. J Clin Sleep Med 16(2):199-206. https://doi.org/10.5664/jcsm.8166

32. Massongo M, Balkissou A, Kenyo C, Sawa B, Kanko N, Pefura E (2020) The STOPBANG score is effective for obstructive sleep apnea syndrome screening and correlates with its features, in a sub-Saharan African population. Pan Afr Med J 36. https://doi. org/10.11604/pamj.2020.36.93.17805

33. Nahapetian R, Silva GE, Vana KD, Parthasarathy S, Quan SF (2016) Weighted STOP-Bang and screening for sleep-disordered breathing. Sleep Breath 20(2):597-603. https://doi.org/10.1007/ s11325-015-1255-2

34. Rebelo-Marques A, Vicente C, Valentim B, Agostinho M, Pereira R, Teixeira MF, Moita J (2018) STOP-Bang questionnaire: the validation of a Portuguese version as a screening tool for obstructive sleep apnea (OSA) in primary care. Sleep Breath 22(3):757765. https://doi.org/10.1007/s11325-017-1608-0

35. Senaratna CV, Perret JL, Lowe A, Bowatte G, Abramson MJ, Thompson B, Lodge C, Russell M, Hamilton GS, Dharmage SC (2019) Detecting sleep apnoea syndrome in primary care with screening questionnaires and the Epworth sleepiness scale. Med J Aust 211(2):65-70. https://doi.org/10.5694/mja2.50145

36. Kunisaki KM, Brown KE, Fabbrini AE, Wetherbee EE, Rector TS (2014) STOP-BANG questionnaire performance in a Veterans Affairs unattended sleep study program. Annals of the American Thoracic Society 11(2):192-197. https://doi.org/10.1513/ AnnalsATS.201305-134OC

37. Lockhart EM, Ben Abdallah A, Tuuli MG, Leighton BL (2015) Obstructive sleep apnea in pregnancy: assessment of current screening tools. Obstet Gynecol 126(1):93-102. https://doi.org/10.1097/ aog.0000000000000848

38. Tantrakul V, Sirijanchune P, Panburana P, Pengjam J, Suwansathit W, Boonsarngsuk V, Guilleminault C (2015) Screening of obstructive sleep apnea during pregnancy: differences in predictive values of questionnaires across trimesters. J Clin Sleep Med 11(2):157163. https://doi.org/10.5664/jcsm.4464

39. Silva GE, Vana KD, Goodwin JL, Sherrill DL, Quan SF (2011) Identification of patients with sleep disordered breathing: comparing the four-variable screening tool, STOP, STOP-Bang, and Epworth Sleepiness Scales. J Clin Sleep Med 7(5):467-472. https://doi.org/10.5664/JCSM.1308

40. Marti-Soler H, Hirotsu C, Marques-Vidal P, Vollenweider P, Waeber G, Preisig M, Tafti M, Tufik SB, Bittencourt L, Tufik S, Haba-Rubio J, Heinzer R (2016) The NoSAS score for screening of sleep-disordered breathing: a derivation and validation study. Lancet Respir Med 4(9):742-748. https://doi.org/10.1016/S22132600(16)30075-3

41. Tan A, Yin JDC, Tan LWL, van Dam RM, Cheung YY, Lee C-H (2016) Predicting obstructive sleep apnea using the STOP-Bang questionnaire in the general population. Sleep Med 27:66-71. https://doi.org/10.1016/j.sleep.2016.06.034

42. Saldias Penafiel F, Brockmann Veloso P, Santin Martinez J, Fuentes-Lopez E, Valdivia CG (2019) Performance of sleep questionnaires for the diagnosis of obstructive sleep apnea syndrome. Revista Medica de Chile 147(12):1543-1552. https://doi.org/10. 4067/S0034-98872019001201543

43. Bauters FA, Loof S, Hertegonne KB, Chirinos JA, De Buyzere ML, Rietzschel ER (2020) Sex-specific sleep apnea screening questionnaires: closing the performance gap in women. Sleep Med 67:9198. https://doi.org/10.1016/j.sleep.2019.10.023

44. Firat H, Yuceege M, Demir A, Ardic S (2012) Comparison of four established questionnaires to identify highway bus drivers at risk for obstructive sleep apnea in Turkey. Sleep \& Biological Rhythms 10(3):231-236. https://doi.org/10.1111/j.1479-8425.2012.00566.x

45. Popević MB, Milovanović A, Nagorni-Obradović L, Nešić D, Milovanović J, Milovanović AP (2017) Screening commercial drivers for obstructive sleep apnea: validation of stop-bang questionnaire. Int J Occupational Med Environ Health 30(5):751-761. https://doi.org/10.13075/ijomeh.1896.00906

46. Watson NF (2016) Health care savings: the economic value of diagnostic and therapeutic care for obstructive sleep apnea. J Clin Sleep Med 12(8):1075-1077. https://doi.org/10.5664/jcsm.6034

47. Marshall NS, Wong KKH, Liu PY, Cullen SRJ, Knuiman MW, Grunstein RR (2008) Sleep apnea as an independent risk factor for all-cause mortality: the Busselton Health Study. Sleep. 31(8): 1079-1085

48. Wharton S, Lau DCW, Vallis M, Sharma AM, Biertho L, Campbell-Scherer D, Adamo K, Alberga A, Bell R, Boulé N, Boyling E, Brown J, Calam B, Clarke C, Crowshoe L, Divalentino D, Forhan M, Freedhoff Y, Gagner M, Glazer S, Grand C, Green M, Hahn M, Hawa R, Henderson R, Hong D, Hung P, Janssen I, Jacklin K, Johnson-Stoklossa C, Kemp A, Kirk S, Kuk J, Langlois MF, Lear S, McInnes A, Macklin D, Naji L, Manjoo P, Morin MP, Nerenberg K, Patton I, Pedersen S, Pereira L, Piccinini-Vallis H, Poddar M, Poirier P, Prud'homme D, Salas XR, Rueda-Clausen C, Russell-Mayhew S, Shiau J, Sherifali D, Sievenpiper J, Sockalingam S, Taylor V, Toth E, Twells L, Tytus R, Walji S, Walker L, Wicklum S (2020) Obesity in adults: a clinical practice guideline. Can Med Assoc J 192(31):E875E891. https://doi.org/10.1503/cmaj.191707

49. Cherrez Ojeda I, Jeffe DB, Guerrero T, Mantilla R, Santoro I, Gabino G, Calderon JC, Caballero F, Mori J, Cherrez A (2013) Attitudes and knowledge about obstructive sleep apnea among Latin American primary care physicians. Sleep Med 14(10):973977. https://doi.org/10.1016/j.sleep.2013.06.005

50. Lombardi C, Musicco E, Bettoncelli G, Milanese M, Senna G, Braido F et al (2015) The perception of obstructive sleep apnoea/ hypopnoea syndrome (OSAHS) among Italian general practitioners. Clin Mol Allergy 13(1):4. https://doi.org/10.1186/s12948015-0009-9

51. Devaraj NK (2020) Knowledge, attitude, and practice regarding obstructive sleep apnea among primary care physicians. Sleep and Breathing 24:1581-1590. https://doi.org/10.1007/s11325-02002040-1

52. Arous F, Boivin JM, Chaouat A, Rumeau C, Jankowski R, Nguyen DT (2017) Awareness of obstructive sleep apnea-hypopnea syndrome among the general population of the Lorraine Region of France. Eur Ann Otorhinolaryngol Head Neck Dis 134(5):303308. https://doi.org/10.1016/j.anorl.2017.02.010

53. Sia C-H, Hong Y, Tan LWL, van Dam RM, Lee C-H, Tan A (2017) Awareness and knowledge of obstructive sleep apnea among the general population. Sleep Med 36:10-17. https://doi.org/10.1016/j. sleep.2017.03.030

54. Arnardottir ES, Bjornsdottir E, Olafsdottir KA, Benediktsdottir B, Gislason T (2016) Obstructive sleep apnoea in the general 
population: highly prevalent but minimal symptoms. Eur Resp J 47(1):194-202. https://doi.org/10.1183/13993003.01148-2015

55. Rapoport DM (2016) POINT: is the apnea-hypopnea index the best way to quantify the severity of sleep-disordered breathing? Yes CHEST 149(1):14-16. https://doi.org/10.1378/chest.15-1319

56. Wolfe RM, Pomerantz J, Miller DE, Weiss-Coleman R, Solomonides $\mathrm{T}$ (2016) Obstructive sleep apnea: preoperative screening and postoperative care. J Am Board Fam Med 29(2):263-275. https://doi.org/10. 3122/jabfm.2016.02.150085

57. Ononye T, Nguyen K, Brewer E (2019) Implementing protocol for obstructive sleep apnea screening in the primary care setting. Appl Nurs Res 46:67-71. https://doi.org/10.1016/j.apnr.2019.02.005

58. Kapur VK, Auckley DH, Chowdhuri S, Kuhlmann DC, Mehra R, Ramar K, Harrod CG (2017) Clinical practice guideline for diagnostic testing for adult obstructive sleep apnea: an American Academy of Sleep Medicine Clinical Practice Guideline. J Clin Sleep Med 13(3):479-504. https://doi.org/10.5664/jcsm.6506

59. Xie W, Chakrabarty S, Levine R, Johnson R, Talmage JB (2011) Factors associated with obstructive sleep apnea among commercial motor vehicle drivers. J Occup Environ Med 53(2)

60. Colvin LJ, Collop NA (2016) Commercial motor vehicle driver obstructive sleep apnea screening and treatment in the United States: an update and recommendation overview. J Clin Sleep Med 12(1):113-125. https://doi.org/10.5664/jcsm.5408

61. Shayestefar M, Sadeghniiat Haghighi K, Jahanfar S, Delvarianzadeh M, Nematzadeh F, Ebrahimi MH (2019) Assessment of the relationship between metabolic syndrome and obstructive sleep apnea in male drivers of Shahroud city in 2018: a cross sectional study. BMC Public Health 19(1):1058. https://doi.org/10.1186/s12889019-7361-5
62. Chung F (2020) Asleep at the controls and a potential problem in flights: is obstructive sleep apnea a public safety concern? Sleep Med. https://doi.org/10.1016/j.sleep.2020.08.016

63. Celikhisar H, Dasdemir IG (2019) The association of obstructive sleep apnea syndrome and accident risk in heavy equipment operators. Medicina (Kaunas) 55(9):599. https://doi.org/10.3390/ medicina55090599

64. Aljurf TM, Olaish AH, BaHammam AS (2018) Assessment of sleepiness, fatigue, and depression among Gulf Cooperation Council commercial airline pilots. Sleep and Breathing. 22(2): 411-419. https://doi.org/10.1007/s11325-017-1565-7

65. Garbarino S, Guglielmi O, Campus C, Mascialino B, Pizzorni D, Nobili L, Mancardi GL, Ferini-Strambi L (2016) Screening, diagnosis, and management of obstructive sleep apnea in dangerousgoods truck drivers: to be aware or not? Sleep Med 25:98-104. https://doi.org/10.1016/j.sleep.2016.05.015

66. Williams JR, Amana A, Tregear SJ. Evidence report: obstructive sleep apnea and commercial motor vehicle driver safety: updated review [11/30/2011]. 2011. https://doi.org/10.21949/1502949

67. de Oliveira ACT, Martinez D, Vasconcelos LFT, Cadaval Gonçalves S, do Carmo Lenz M, Costa Fuchs S et al (2009) Diagnosis of obstructive sleep apnea syndrome and its outcomes with home portable monitoring. Chest 135(2):330-336. https://doi. org/10.1378/chest.08-1859

Publisher's note Springer Nature remains neutral with regard to jurisdictional claims in published maps and institutional affiliations. 